\title{
Percepção socioambiental da população sobre eventos de erosão costeira no litoral de Atafona, Rio de Janeiro, Brasil
}

\section{Socioenvironmental perception of the population to coastal erosion events on the coast of Atafona, Rio de Janeiro, Brazil}

\author{
Luana Aparecida Castro Firmino $ه(\mathbb{D}$, Lázaro Dias Alves* $₫(\mathbb{D}$ \\ Laboratório de Geografia Física, Instituto de Ciências da Sociedade e Desenvolvimento Regional, \\ Universidade Federal Fluminense, Campos dos Goytacazes, Rio de Janeiro, Brasil \\ E-mail: luanacastro@id.uff.br \\ *E-mail para correspondência: lazarodias@id.uff.br
}

Recebido (Received): 12/08/2020 Aceito (Accepted): 07/05/2021

\begin{abstract}
Resumo: Em Atafona, norte do estado do Rio de Janeiro ocorre um intenso processo erosivo que causa prejuízos às atividades econômicas da região. Portanto, o objetivo do estudo é analisar a percepção socioambiental da população sobre o processo de erosão costeira, que vem ocorrendo há décadas na região. Entrevistas foram realizadas a partir de um questionário semiestruturado, organizado em três categorias de análise: 1) caracterização dos entrevistados; 2) percepção da paisagem costeira e; 3) gestão costeira integrada. De acordo com os entrevistados, a erosão costeira na região está associada ao 'avanço do mar' e 'ações antropogênicas'. Os aspectos negativos mais citados são: perda de construções (imóveis residenciais e comerciais); redução do valor dos imóveis e redução da pesca. As informações obtidas mostram que nenhuma ação é tomada pelo governo para mitigar o problema da erosão, e não há medidas de envolvimento e consulta da população para identificar as causas e consequências do fenômeno.
\end{abstract}

Palavras-chave: Gerenciamento costeiro integrado; Zona costeira; Avanço do mar.

Abstract: In Atafona, north of the state of Rio de Janeiro there is an intense erosive process that causes damage to the economic activities of the region. Therefore, the objective of the study is to analyze the population's socio-environmental perception of the coastal erosion process, that has been occurring for decades in the region. Interviews were conducted based on a semistructured questionnaire, organized into three categories of analysis: 1) characterization of interviewees; 2) perception of the coastal landscape; 3) integrated coastal management. According to the interviewees, coastal erosion in the region is associated with 'advance the sea' and 'anthropogenic actions'. The most cited negative aspects are: loss of constructions (residential and commercial properties; reduction in the value of real properties and fishing reduction. The information obtained shows no action is taken by the government to mitigate the erosion problem, and there are no measures for the involvement and consultation of the population to identify the causes and consequences of the phenomenon.

Keywords: Integrated coastal management; Coastal zone; Advance of the sea

\section{Introdução}

A zona costeira é um ambiente dinâmico que está constantemente sobre influência de eventos extremos. O processo de erosão é intensificado pela passagem de eventos de alta energia na costa, que comprometem as atividades desenvolvidas pelas populações nas regiões litorâneas (LINS-DE-BARROS et al., 2016). É um fenômeno global que vem sendo impulsionado pela ocupação desenfreada do litoral, que acarreta riscos potencialmente elevados de perdas por erosão (MUEHE, 2001). Nesse sentido, a erosão costeira configura-se como um problema socioambiental de cunho econômico e também político que cabe às instâncias públicas o seu papel de identificação e mitigação (MEDEIROS et al., 2014). 
O litoral norte fluminense apresenta tendência erosiva, sendo caracterizado pela alteração e deterioração da paisagem costeira (DIAS; GORINI, 1980; MUEHE et al., 2006; RIBEIRO et al., 2016). Um dos compartimentos que divide este litoral é o macrocompartimento da Bacia de Campos (Litoral Oriental) que se estende da barra do rio Itabapoana à barra do rio Paraíba do Sul em Atafona. Este macrocompartimento apresenta características erosivas, visíveis na retrogradação das falésias e nos trechos urbanizados da planície arenosa (MUEHE et al., 2006). A localidade de Atafona encontra-se nesta região, que apresenta um total de 183 construções e 14 quadras destruídas pelos processos erosivos (MELLO et al., 2018).

A percepção socioambiental da população local pode contribuir para o gerenciamento das zonas costeiras, pois é a visão dos atores sociais que estão em contato direto com os efeitos advindos dos processos naturais. A junção entre conhecimento científico e popular constitui o meio mais viável e eficiente para a mitigação de problemas (DELICADO et al., 2012; SEIXAS et al., 2014; LINS-DE-BARROS et al., 2016). Sendo assim, o gerenciamento deve envolver atores locais, gestores, empresas, instituições de pesquisa e responsáveis por empreendimentos regionais (SILVEIRA, 2011; BERTAPELI, 2012).

Assim, mostra-se necessária a execução de estudos que abordem a percepção das populações litorâneas frente aos eventos de erosão costeira a fim de melhor compreender sua interferência sobre a economia e turismo local. Nesse contexto, o presente trabalho objetivou realizar o diagnóstico da percepção socioambiental da população da localidade de Atafona sobre o processo de erosão costeira na área.

\section{Materiais e métodos}

\section{1. Área de estudo}

O estudo foi realizado no distrito de Atafona, localizado no município de São João da Barra, litoral norte do estado do Rio de Janeiro (Figura 1). O distrito possui cerca de 6.799 habitantes, sendo que dos 23.618 domicílios que existem no município, $44 \%$ são de uso ocasional, principalmente nas áreas litorâneas do município como as do distrito de Atafona, demonstrando o forte perfil turístico local (TCE-RJ, 2017). O maior crescimento demográfico do município ocorreu principalmente a partir de 2006 com o início das obras do Complexo Portuário do Açu (DEODATO et al., 2019). A economia municipal está fortemente ligada aos setores de administração pública, serviços, construção civil e indústria de transformação, sobretudo com a chegada do empreendimento portuário na região (DEODATO et al., 2019).
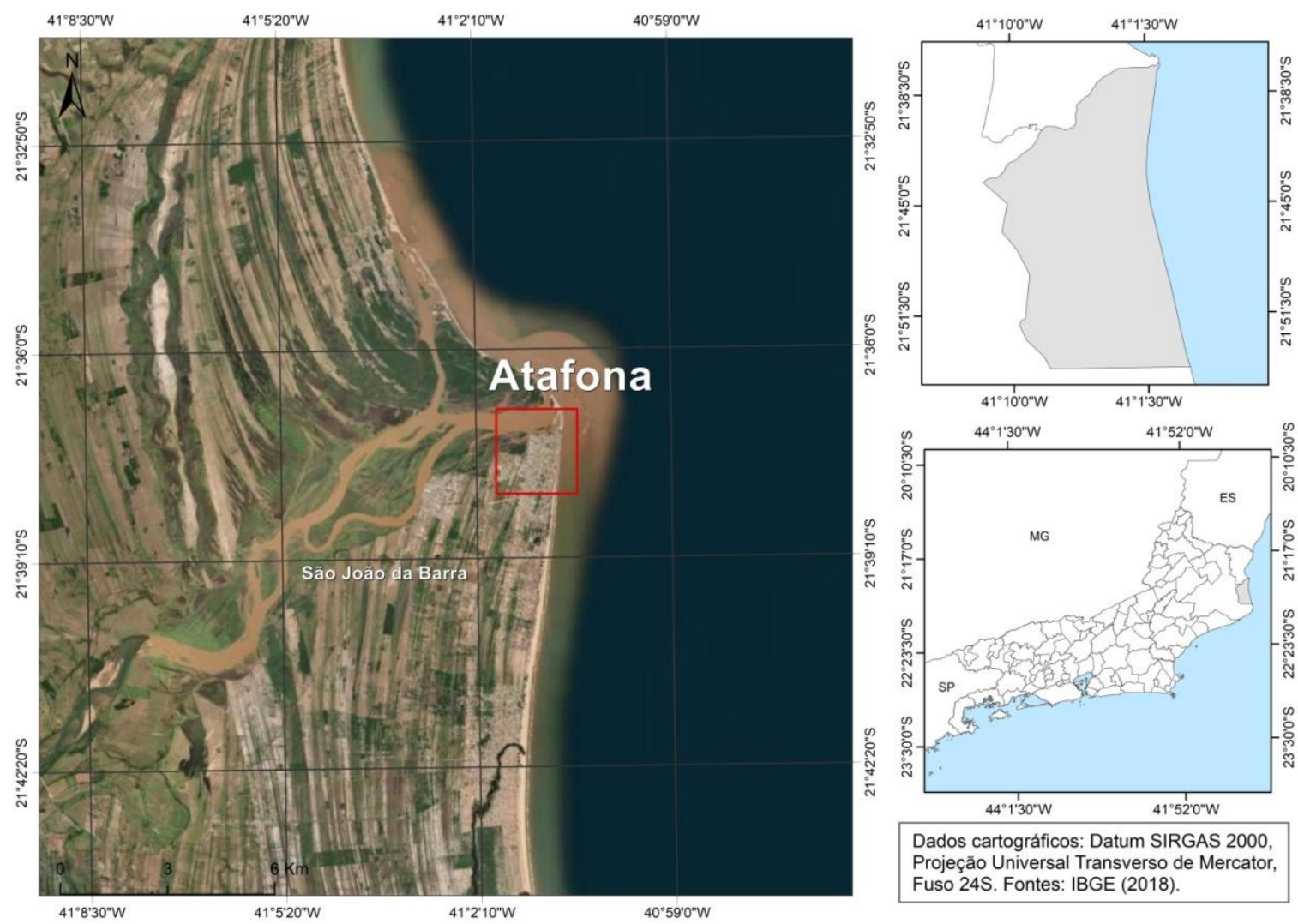

Figura 1: Localização de Atafona, litoral norte do estado do Rio de Janeiro, Brasil. 
Em 2014, o município o qual pertence o distrito de Atafona apresentou o maior PIB per capita do estado do Rio de Janeiro no valor de R $\$ 258.723,38$, sendo esse desempenho altamente articulado ao setor petrolífero (DEODATO et al., 2019). Apesar disso, o município em questão sofre com a concorrência do centro polarizador de Campos dos Goytacazes, município também presente no norte fluminense que inibe suas funções urbanas no contexto regional (TCE-RJ, 2017).

A pesca também é uma importante atividade econômica e cultural realizada no distrito de Atafona, uma vez que o distrito surgiu a partir de uma aldeia de pescadores em 1622 (CAMPINHO; ARRUDA, 2019). O distrito de Atafona é a principal área de desembarque pesqueiro do município de São João da Barra. Em 2017, o município foi o terceiro maior produtor da região norte fluminense com uma produção total de 701,9 toneladas desembarcadas, sendo 75,4\% (529,4 t) provenientes da frota artesanal e 24,6\% (172,5 t) da frota industrial (FIPERJ, 2017).

O distrito de Atafona está inserido no macrocompartimento da Bacia de Campos, sendo este segmento do litoral caracterizado por falésias ativas e planícies arenosas estreitas (MUEHE, 2006). Em tal segmento do litoral brasileiro predominam processos erosivos intensos (RIBEIRO et al., 2016). As feições resultantes deste processo são ocasionadas pela direção incidente e a frequência das ondas que chegam neste litoral, bem como os mecanismos relacionados às descargas fluviais (DIAS; GORINI, 1980). Neste pequeno trecho predomina o mais intenso fenômeno erosivo de todo o litoral do estado do Rio de Janeiro (MUEHE, 2006). A velocidade com que a erosão tem atuado na área de estudo chega a alcançar uma taxa de 7,8m/ano (RIBEIRO et al., 2005).

A configuração da linha de costa da região norte fluminense apresenta-se direcionada para nor-nordeste e su-sudoeste, interrompida pela larga planície progradacional do rio Paraíba do Sul, que expõe a linha de praia a diferentes direções de incidência das ondas (BASTOS; SILVA, 2000; MUEHE et al, 2006). A morfologia da área de estudo é caracterizada por uma planície sedimentar desenvolvida por processos de sedimentação flúviomarinha, cujas barreiras arenosas são dispostas de acordo com a incidência das ondas (SUGUIO et al., 2005). A evolução da planície costeira do rio Paraíba do Sul é caracterizada por depósitos marinhos de dois períodos distintos, sendo os terraços pleistocênicos os mais antigos e os holocênicos os mais recentes (SUGUIO et al., 1985).

A localidade de Atafona situa-se na Zona Tropical e sofre influência do Anticiclone Subtropical do Atlântico Sul (SOUZA et al., 2015). As temperaturas médias do ar variam entre $24^{\circ}$ a $27^{\circ} \mathrm{C}$ no verão e $21^{\circ}$ a $24^{\circ} \mathrm{C}$ no inverno, com ventos predominantes de nordeste e rajadas ocasionais de sudoeste associadas à passagem de frentes frias e ciclones extratropicais pela área (SOUZA et al., 2015). As condições mais frequentes de entrada de ondas são de nordeste e leste, expondo a maioria das praias deste litoral (SOUZA et al., 2015).

\subsection{Procedimentos metodológicos}

Neste estudo foram realizadas 20 entrevistas semiestruturadas aos moradores locais da localidade de Atafona, município de São João da Barra, norte do estado do Rio de Janeiro (DELICADO et al., 2012; LINS-DE-BARROS et al., 2016). Durante as entrevistas semiestruturadas seguimos um conjunto de questões previamente definidas em um contexto semelhante ao de uma conversa informal (BONI; QUARESMA, 2005). Estas foram realizadas por meio de diálogos, pois deste modo é facilitada a interação e o estabelecimento de confiança entre entrevistador e entrevistado (BONI; QUARESMA, 2005). A fim de minimizar a interferência de outro entrevistado durante o diálogo, cada entrevista foi conduzida individualmente. $\mathrm{O}$ número de entrevistas aplicadas no estudo é justificado pelo motivo de que em estudos que envolvem percepção local percebe-se que a partir da décima entrevista há um padrão de respostas denominado por 'ponto de saturação', que consiste no momento em que as respostas começam a se repetir (THIRY-CHERQUES, 2009).

Como sugerido por Sanches (2004), a seleção do primeiro entrevistado ocorreu através de um guia local, já que geralmente é aquele que melhor conhece os atores locais. A partir do segundo entrevistado foi utilizada a técnica bola-de-neve (BAILEY, 1982), no qual um potencial entrevistado é indicado pelos membros da comunidade que já responderam ao questionário. Durante a entrevista foram utilizadas expressões e palavras locais a fim de gerar maior confiança entre as partes, com aproximação da linguagem local (COSTA-NETO; MARQUES, 2000). As informações obtidas durante as entrevistas foram guiadas por um questionário padrão contendo questões abertas e fechadas, funcionando como suporte para a entrevista (MELO, 2004). Este tipo de entrevista segue um esquema pré-estabelecido, mas não rígido, exibindo certa flexibilidade e permitindo que o entrevistador faça as adaptações necessárias (KENDALL, 2008). 


\subsection{Análise dos dados}

Os relatos foram organizados em categorias relacionadas às questões do questionário (RYAN; BERNARD, 2000). Desta maneira, foi possível agrupar as informações por temas como meio de classificar os relatos e, com isso, facilitar a interpretação das entrevistas (BOGDAN; BIKLEN, 1994; BONI; QUARESMA, 2005; ROCHA; DEUSDARÁ, 2005). Para a validação dos relatos foi utilizado o método da Triangulação, cujo objetivo é cruzar e filtrar informações coletadas com as demais técnicas aplicadas (observação direta, diário de campo, entrevistas-questionários e registro fotográfico (TEIS; TEIS, 2006). Para tanto, foi aplicado o mesmo questionário para diferentes sujeitos em períodos de tempo variados (GOLDENBERG, 2004; MELO, 2004). Desse modo, foi possível obter a veracidade máxima nos relatos e estabelecer as ligações entre as informações contidas nas falas para a construção das análises (NEVES, 1996; GOLDENBERG, 2004; SILVA; FOSSÁ, 2015).

\section{Resultados e discussão}

\subsection{Caracterização dos entrevistados}

Os entrevistados abordados neste estudo foram em sua maior parte do sexo masculino $(70 \%$; $n=14)$ e em menor proporção do sexo feminino (30\%; $\mathrm{n}=6$ ). A faixa etária dos entrevistados variou dos 20 aos 62 anos, com predominância dos 20 aos 30 anos. Os entrevistados foram de meia idade e, geralmente foram os filhos de pessoas que já perderam propriedades por conta dos eventos de erosão costeira na região. A maior parte dos entrevistados possui o ensino médio completo $(40 \% ; n=8)$ e afirmaram ter nascido na região (80\%; $\mathrm{n}=16$ ). Já os entrevistados que alegaram não ter nascido na região, moram no local a aproximadamente 5 a 25 anos.

\subsection{Percepção da paisagem frente à erosão costeira}

Quanto à percepção da paisagem em relação ao problema da erosão costeira, 95\% (n=19) dos entrevistados consideram a ação do mar como principal desencadeador de processos erosivos na costa. $\mathrm{O}$ 'avanço do mar' $(45 \%$; $n=9)$ foi apontado como o principal problema na região, seguido pela 'formação de ciclones' $(20 \%$; $(n=4)$. O 'derretimento de geleiras' e as 'mudanças climáticas' $(30 \%$; $n=6)$ também foram mencionados pelos entrevistados. As respostas demostraram a compreensão da população em relação aos problemas erosivos e suas consequências na área.

Estes resultados corroboraram com o encontrado por Modesto e Carmo (2014) para a praia de Ilha Comprida, litoral Sul de São Paulo, no qual os entrevistados também apontaram o avanço do mar como problema principal da erosão. É possível destacar, que a percepção é bem restrita ao cotidiano e ao modo de vida tradicional, visto que a maioria cita a importância do mar ao seu dia a dia, não considerando a saída do local. Isso mostra o papel que o mar representa no convívio das pessoas que moram, trabalham ou frequentam as praias (LINS-DE-BARROS et al., 2016).

A praia de Atafona é um grande exemplo de perda de valor paisagístico e turístico em detrimento do processo de erosão costeira (Figura 2), pois a maioria dos entrevistados $(95 \%$; $=19)$ atribuiu algum aspecto negativo ao processo erosivo. A perda de estrutura urbana e de imóveis residenciais e comerciais foram os aspectos mais citados pela população entrevistada $(60 \% ; n=12)$. Já a perda de valor imobiliário foi mencionada por $20 \%$ dos entrevistados $(n=4)$, que está relacionado à paisagem de destruição que se criou pela perda da faixa praial (Tabela 1).

A perda considerável da faixa de praia causa prejuízos às atividades socioeconômicas tradicionais em diversas porções do litoral brasileiro (SOUZA; LUNA, 2009). A redução da pesca $(15 \% ; n=3)$ foi citada pela população residente como uma caraterística prejudicial à economia local. Os processos erosivos atuantes na costa influem no distanciamento do pescado para mar aberto fazendo com que os pontos de pesca sejam menos acessíveis (SILVA, 2015).

A erosão costeira é um fenômeno global que afeta milhares de pessoas que vivem próximas às regiões litorâneas. A respeito do índice de importância que a população local atribuiu à erosão costeira, $85 \%(n=17)$ considera o processo importante. Quanto à atuação antrópica nos ambientes costeiros, $80 \%$ (n= 16) dos entrevistados alegaram existir relação com a intensificação da erosão costeira. A grande maioria atribuiu as causas à instalação do Complexo Portuário do Açu em São João da Barra, e também a construção de residências muito próximas à praia. 


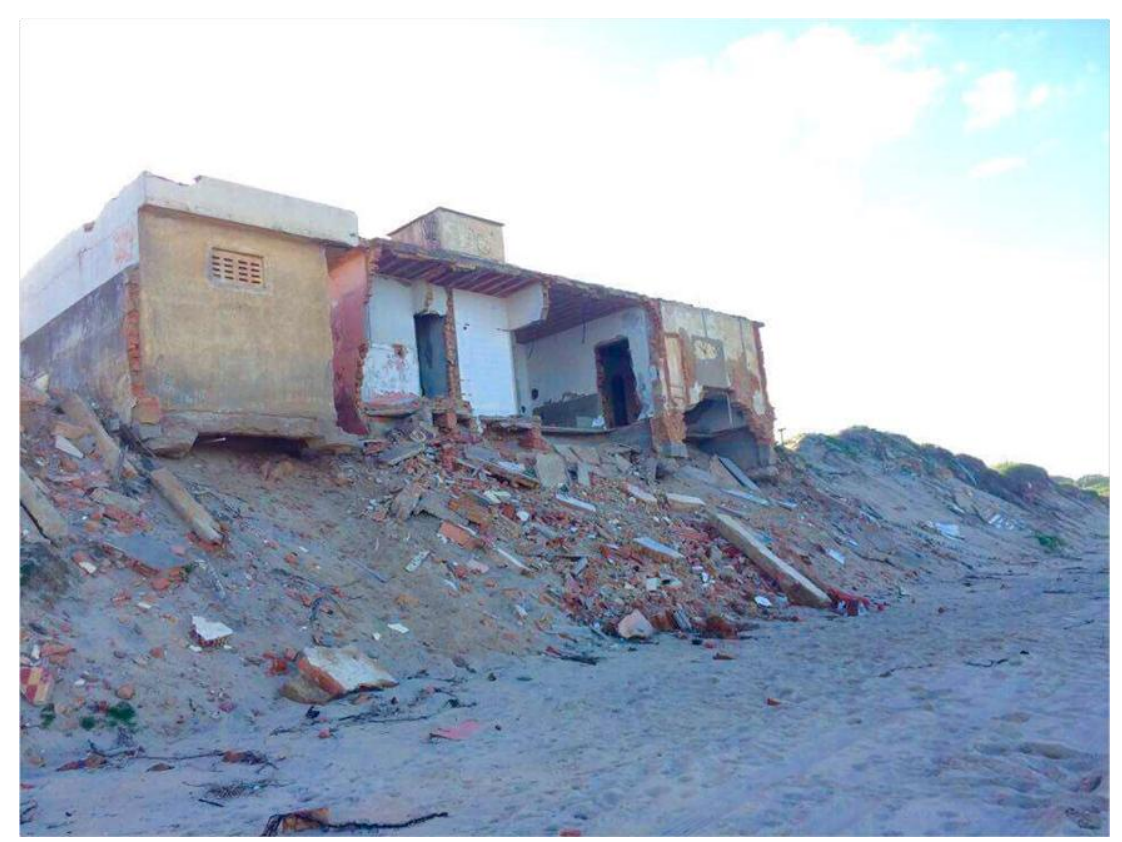

Figura 2: Impactos da erosão costeira na localidade de Atafona, Rio de Janeiro, Brasil. Fonte: Acervo dos autores, 2018.

Tabela 1: Aspectos negativos apontados pelos entrevistados em relação aos eventos de erosão costeira.

\begin{tabular}{lcc}
\hline Aspectos & n & \% \\
\hline Perda de construções & 12 & 60 \\
Perda de valor imobiliário & 4 & 20 \\
Redução da pesca & 3 & 15 \\
Não sabe & 1 & 5 \\
\hline Total & 20 & 100 \\
\hline
\end{tabular}

Fonte: Elaborado pelos autores, 2018.

Estes resultados são concordantes com o encontrado por Medeiros et al. (2014) para a localidade de Taíba, no litoral oeste do estado do Ceará, na qual $82 \%$ da população entrevistada confirmaram a relação entre processos erosivos e interferências antrópicas. Muehe (2005) e Dominguez et al. (2006) afirmaram que $80 \%$ das causas de erosão costeira no Brasil estão relacionadas à intervenção e interferência da sociedade próximo a desembocaduras fluviais e segmentos urbanizados localizados em praias.

\subsection{Gerenciamento costeiro integrado}

Os entrevistados quando foram questionados a respeito de já haver tido alguma medida tomada por representantes e gestores locais para a mitigação da erosão costeira na região, a maior parte afirmou que nenhuma ação é tomada para a contenção do problema $(90 \%$; $n=18)$ e apenas dois dos entrevistados afirmaram não saber $(10 \% ; n=2)$. Os mesmos ainda afirmaram que nenhum representante local se interessa em um projeto desse porte, pois além de ser um empreendimento caro, a construção exige manutenção periódica, aumentando o custo da obra. Isso ocorre, pois ainda são embrionárias as diretrizes e ações do poder público para lidar com os problemas costeiros e suas causas e, embora o tema seja amplamente abordado nas instituições de pesquisa em Geociências de todo o país, as políticas de planejamento e ordenamento territorial, em especial aquelas na esfera da gestão costeira, pouco têm incorporado os conhecimentos adquiridos, que resulta muita das vezes no desperdício de recursos financeiros públicos com a implantação de obras de engenharia costeira que acabam acelerando ainda mais o processo erosivo (SOUZA, 2009).

Todos os entrevistados alegaram nunca ter ouvido falar na proposta de 'Gerenciamento Costeiro Integrado' $(100 \%$; $\mathrm{n}=20)$, que se refere a um gerenciamento elaborado em etapas e com a opinião da população que vive cotidianamente com o problema a ser enfrentado. Em uma perspectiva mais abrangente $\mathrm{e}$ integrada de gestão costeira, a Constituição Federal definiu em seu artigo 225, a zona costeira como patrimônio nacional, enquanto a Lei Federal 7.661 instituiu o Plano Nacional de Gerenciamento Costeiro PNGC (VIANNA; POLETTE, 2012). O desconhecimento do Plano Nacional de Gerenciamento Costeiro por parte da população é comum em todo o Brasil, pois não há o envolvimento e consulta da população nas 
etapas da tomada de decisão e, é o grupo que mais acaba sofrendo, sendo afetados diretamente (DELICADO et al., 2012). A gestão participativa é fundamental num processo dessa natureza, uma vez que favorece consenso entre conflitos, diálogo institucional, transparência legal e justificativa técnica e científica num espaço de discussão aberto para a sociedade (SOUZA, 2009).

De fato, existe uma ausência de medidas tomadas pelo poder público para conter o processo de erosão no distrito de Atafona. No entanto, reuniões com o ministério público estadual, representantes municipais e pesquisadores estão ocorrendo nos últimos anos para apresentação de proposta técnica para contenção do mar na região, tendo como base obras de engenharia como a instalação de espigões e engordamento artificial da praia. Na Tabela 2 são apresentadas algumas soluções técnicas propostas durante as reuniões e que devem ser levadas em consideração para o engordamento artificial da praia.

Tabela 2: Soluções técnicas para o engordamento artificial da praia de Atafona.

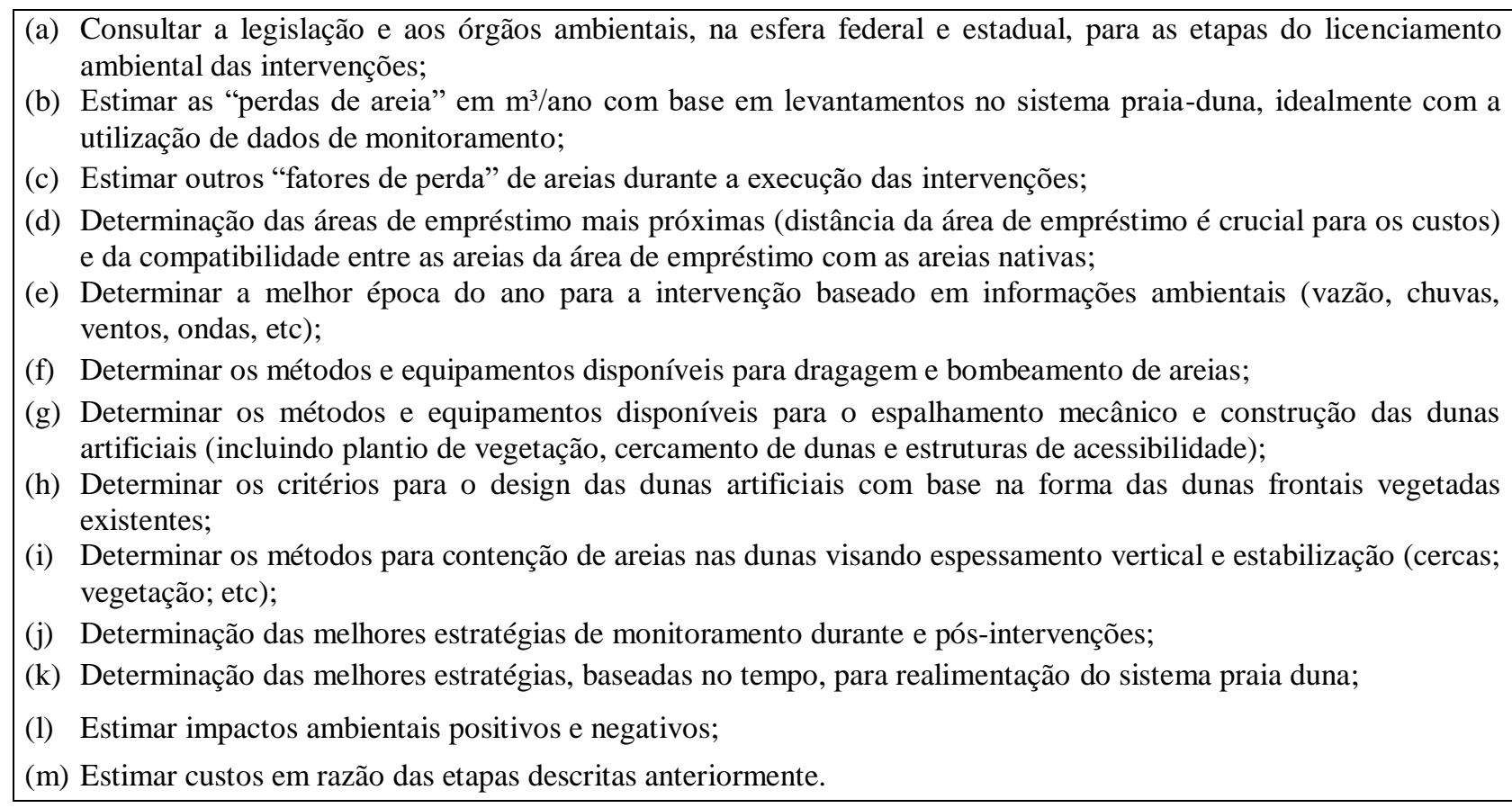

Fonte: Bulhões, 2018.

De acordo com os relatos há algumas formas da população local ajudar a proteger a costa contra os eventos de erosão costeira $(75 \% ; n=15)$. Apenas $20 \%(n=4)$ acham que não é possível fazer nada contra a ação erosiva e 5\% $(n=1)$ não souberam responder. As propostas são apresentadas na Tabela 3. O número de respostas menor do que o número de entrevistados se justifica porque alguns entrevistados não souberam responder à questão $(20 \% ; n=4)$. Para os entrevistados as reuniões públicas periódicas e a construção de uma associação local seriam fundamentais para a identificação dos problemas na costa, assim como as medidas mitigadoras a serem tomadas para a resolução dos problemas, pois a população possui uma incapacidade de reivindicação, só parcialmente ultrapassada quando estes são representados em associações ou sindicatos (DELICADO et al., 2012).

Tabela 3: Propostas apresentadas pelos entrevistados frente aos eventos de erosão.

\begin{tabular}{lcc}
\hline Proposta & N & \% \\
\hline Reuniões públicas com a prefeitura local & 9 & 45 \\
Construir uma associação que cuide do assunto & 5 & 25 \\
Diminuição da poluição & 2 & 10 \\
\hline Total & 16 & 80 \\
\hline
\end{tabular}

Fonte: Elaborado pelos autores, 2018.

A maior parte dos entrevistados afirmou possuir uma forma de se adaptar frente aos eventos de erosão costeira na região $(75 \% ; n=15)$. De acordo com os relatos a forma que eles possuem é não adquirindo propriedades próximas à costa, ainda que os valores dos terrenos, lotes e casas estejam consideravelmente 
acessíveis, pois é um ambiente dinâmico e está sujeito constantemente aos eventos de erosão. A compreensão da percepção e das adaptações da população aos desastres naturais, assim como dos danos e prejuízos financeiros, tem sido considerada cada vez mais relevante para o desenvolvimento de adequados programas de gestão e planejamento em áreas de risco (LINS-DE-BARROS et al., 2016).

A perda considerável de faixa de praia tem ocasionado prejuízos às atividades socioeconômicas e comprometido o potencial turístico local (SOUZA; LUNA, 2009). A população que vive próxima ao ambiente costeiro tem uma visão privilegiada das mudanças costeiras e, em resultado da sua vivência, detêm um conhecimento que, apesar de não ser técnico, se baseia na experiência e é específico ao local (DELICADO et al., 2012). Entretanto, as pesquisas não avaliam a percepção ambiental dos utilizadores das zonas costeiras, buscando um melhor entendimento a respeito das necessidades humanas e ambientais que compõem a realidade do local (MEDEIROS et al., 2014).

O estabelecimento de maior diálogo entre poder público, população local e especialistas contribuiria para a melhor compreensão da problemática, orientando assim de forma mais adequada futuras ações (LINS-DEBARROS et al., 2016). O conhecimento local da comunidade deve ser integrado nos procedimentos de investigação e planejamento costeiro, que por sua vez permitirá o desenvolvimento de subsídios para a criação de métodos de adaptação e resiliência da comunidade, frente às mudanças do ambiente costeiro (DELICADO et al., 2012; MEDEIROS et al., 2014).

\section{Considerações finais}

O presente estudo buscou compreender a percepção da população de Atafona sobre o processo de erosão costeira, apontando os problemas ambientais enfrentados na localidade. A maior parte da população apontou o avanço do mar como indutor dos problemas ocasionados na área, sendo responsável principalmente pela perda de construções e a perda de valor dos imóveis localizados próximos às áreas de erosão. A maioria dos entrevistados reside a um tempo consideravelmente longo na localidade, o que os torna aptos a descrever as causas e implicações dos eventos de erosão costeira da área, já que este não é um processo recente. Logo, a população residente possui um conhecimento específico que pode contribuir com as propostas de planejamento e gestão.

No entanto, a gestão do problema na região depende apenas da iniciativa pública, visto que propostas técnicas para a gestão do problema já foram apresentadas por especialistas durante reuniões governamentais. Além disso, é necessário consultar a opinião da população desta região sobre as propostas apresentadas durante essas reuniões, de modo a cumprir os princípios do Gerenciamento Costeiro Integrado presentes no Plano Nacional de Gerenciamento Costeiro (PNGC).

\section{Referências}

BASTOS, A.C.; SILVA C.G. Caracterização Morfodinâmica do Litoral Norte Fluminense, RJ, Brasil. Revista Brasileira de Oceanografia, v. 48, p. 41-60, 2000. https://doi.org/10.1590/S141377392000000100004

BAILEY, K.D. Methods of Social Research. 4. ed. Nova York: Free Press, 1982. 824 p.

BERTAPELI, V. Sentir para conhecer: As percepções dos pescadores artesanais sobre os impactos ambientais causados pelas mudanças climáticas. Revista de Iniciação Científica da FFC, v. 12, p. 1-16, 2012. https://doi.org/10.36311/1415-8612.2012.v12n1.1667

BONI, V.; QUARESMA, S.J. Aprendendo a entrevistar: como fazer entrevistas em Ciências Sociais. Em Tese, v. 2, p. 68-80, 2005. https://doi.org/10.5007/\%25x

BULHÕES, E.M.R. Relatório Técnico No 01/2018. Erosão costeira e avanço do mar na localidade de Atafona. Causas, Consequências e Propostas de Intervenção. Defensoria Pública do Estado do Rio de Janeiro. Núcleo de Primeiro Atendimento da Comarca de São João da Barra-RJ. Campos dos Goytacazes: Unidade de Estudos Geocosteiros, 2018. https://www.researchgate.net/project/GeoCosteira-Unidade-deEstudos-Costeiros 
CAMPINHO, A.L.M.C.; ARRUDA, A.P.S.N. Índice de Vulnerabilidade Social do município de São João da Barra dentro do espectro do Norte Fluminense. Boletim Petróleo, Royalties e Região, n. 63, p. 43-52, 2019. https://royaltiesdopetroleo.ucam-campos.br/boletins/boletim-agosto-2019/

COSTA-NETO, E.M.; MARQUES, J.G.W. A etnotaxonomia de recursos ictiofaunísticos pelos pescadores da comunidade de Siribinha, Norte do Estado da Bahia, Brasil. Biociências, v. 8, p. 61-76, 2000.

DELICADO, A.; SCHMIDT, L.; GUERREIRO, S.; GOMES, K. Pescadores, conhecimento local e mudanças costeiras no litoral Português. Revista de Gestão Costeira Integrada, v. 12, p. 437-451, 2012. https://doi.org/10.5894/rgci349

DEODATO, I.A.; SANTOS, V.J.; TRAMONT, G.A.G. As mudanças ocorridas na configuração sócio política do município de São João da Barra: a implantação do Porto do Açu. Seminário Internacional sobre Desenvolvimento Regional: Processos, Políticas e Transformações Territoriais, v. 3, p. 1-19, 2019.

DIAS, G.T.M.; GORINI, M.A.A. Baixada Campista: Estudo Morfológico dos Ambientes Litorâneos. In: CONGRESSO BRASILEIRO DE GEOLOGIA, 31.; 1980, Camboriú. Anais... São Paulo,1980. p. 588-602.

DOMINGUEZ, J.M.L.; BITTENCOURT, A.S.; SANTOS, A.N.; ANDRADE, A.C.S.; LAVENEREWANDERLEY, A.M.O.; SILVA, I.R.; QUEIROZ, I.G.; FREITAS, L.B.; NASCIMENTO, L.; SILVA, R.P. Erosão e Progradação do Litoral da Bahia. In: MUEHE, D. (org.). Erosão e Progradação no litoral brasileiro. Brasília: MMA, 2006. p. 219-225.

FIPERJ, FUNDAÇÃO INSTITUTO DE PESCADA DO ESTADO DO RIO DE JANEIRO. Dados da produção pesqueira marinha. Julho a Dezembro de 2017. Região Norte Fluminense. Rio de janeiro: Fundação Instituto de Pescada do Estado do Rio de Janeiro, 2017. http://www.fiperj.rj.gov.br/index.php/publicacao/index/1

GOLDENBERG, M. A arte de pesquisar: como fazer pesquisa qualitativa em Ciências Sociais. 8. ed. São Paulo: Record, 2004. 99 p.

KENDALL, L. The conduct of qualitative interview: Research questions, methodological issues, and researching online. In: COIRO, J.; KNOBEL, M.; LANKSHEA, C.; LEU, D.J. (eds.). Handbook of research on new literacies. Nova York: Lawrence Erlbaum Associates, 2008. p. 133-149.

LINS-DE-BARROS, F.M.; ZEIDAN, F.; LIMA, R.F. Adaptações e percepção da população a eventos de ressaca do mar no litoral de Maricá, Rio de Janeiro, Brasil. Revista de Gestão Costeira Integrada, v. 16, p. 147-161, 2016. https://doi.org/10.5894/rgci591

MEDEIROS, E.C.S; PANTALENA, A.F; MIOLA, B.; LIMA, R.S; SOARES, M.O. Percepção ambiental da erosão costeira em uma praia no litoral do Nordeste do Brasil (Praia da Taíba, CE). Revista de Gestão Costeira Integrada, v. 14, p. 471-482, 2014. https://doi.org/10.5894/rgci488

MELLO, G.S.; MACHADO, B.A.; ROCHA, T.B. Avaliação dos Impactos da Erosão Costeira no Distrito de Atafona (RJ), entre os anos de 2005 e 2016.In: SIMPÓSIO NACIONAL DE GEOMORFOLOGIA, 12.; 2018, Crato. Anais... Crato, 2018.

MELLO, L.G. Antropologia cultural: iniciação, teoria e temas. In: MELLO, L.G. (org.). Antropologia cultural: iniciação, teoria e temas. 11. ed. Petrópolis: Editora Vozes, 2004. p. 33-78.

MODESTO, F.; CARMO, R.L. Riscos ambientais, percepção e adaptação em zonas costeiras: o caso de Ilha Comprida. Revista Espinhaço, v. 3, p. 24-42, 2014. https://doi.org/10.5281/zenodo.3966188

MUEHE, D. Critérios Morfodinâmicos para o Estabelecimento de Limites da Orla Costeira para fins de Gerenciamento. Revista Brasileira de Geomorfologia, v. 2, p. 35-44, 2001. http://dx.doi.org/10.20502/rbg.v2i1

MUEHE, D. Aspectos Gerais da Erosão Costeira no Brasil. Revista de Geografia da UFC, v. 4, p. 97-110, 2005. http://www.mercator.ufc.br/mercator/issue/view/M7 
MUEHE. D.; LIMA, C.F.; BARROS, F.M. Erosão e Progradação do Litoral do Rio de Janeiro. In: MUEHE, D. (org.). Erosão e Progradação do Litoral Brasileiro. Brasília: MMA, 2006. p. 265-296.

NEVES, J.L. Pesquisa Qualitativa: características, usos e possibilidades. Caderno de Pesquisas em Administração, v. 1, p. 1-5, 1996.

RIBEIRO, G.P.; FIGUEIREDO, J.R.A.G.; ROSAS, R.O. Processos costeiros: erosão em Atafona e progradação em Grussaí, São João da Barra (RJ) - Morfometria para retração espacial desses eventos e identificação de sua tendência evolutiva. In: SIMPÓSIO NACIONAL DE GEOMORFOLOGIA, 6.; 2006, Goiânia. Anais... Goiânia, 2006. p. 1-12.

RIBEIRO, M.G.; GOMES, T.B.; BULHÕES, E.M.R. Respostas morfodinâmicas e fisiográficas da zona costeira ao norte da bacia de Campos frente à eventos de tempestade. Revista Tamoios, v. 12, p. 91-111, 2016. https://doi.org/10.12957/tamoios.2016.16832

RYAN, G.; BERNARD, H.R. Data management and analysis methods. In: DENZIN, N.K., LINCOLN, Y.S. (eds.). Handbook of Qualitative Research. 2. ed. Londres: Sage, 2000. p. 769-802.

SANCHES, R.A. Estação Ecológica Juréia-Itatins. In: MARQUES, O.A.V.; DULEBA, W. (eds.). Caiçaras e a Estação Ecológica de Juréia-Itatins. Histórico de ocupação no contexto político, econômico, social e ambiental do Vale do Ribeira. Ribeirão Preto: Holos Editora, 2004. p. 349-359.

SEIXAS, S.R.C.; HOEFFEL, J.L.M.; RENK, M.; SILVA, B.N.; LIMA, F.B. Percepção de pescadores e maricultores sobre mudanças ambientais globais, no litoral Norte Paulista, São Paulo, Brasil. Revista de Gestão Costeira e Integrada, v. 14, p. 51-64, 2014. https://doi.org/10.5894/rgci424

SILVEIRA, C.D. A pesca artesanal no contexto Português: o conhecimento local na solução de conflitos. Tempos Históricos, v. 15, p. 383-404, 2011.

SILVA, L.A. Com vento a lagoa vira mar: uma etnoarqueologia da pesca no litoral norte do RS. Boletim do Museu Paraense Emílio Goeldi, v. 10, p. 537-547, 2015. https://doi.org/10.1590/198181222015000200016

SOUZA, T.A.; BULHÕES, E.; AMORIM, I.B.S. Ondas de tempestade na costa Norte Fluminense. Quaternary and Environmental Geosciences, v. $6, \quad$ p. $10-17, \quad 2015$. http://dx.doi.org/10.5380/abequa.v6i2.41139

SOUZA, C.R.G. A Erosão Costeira e os Desafios da Gestão Costeira no Brasil. Revista da Gestão Costeira Integrada, v. 9, p. 17-37, 2009. https://www.doi.org/10.5894/rgci147

SOUZA, C.R.G.; LUNA, G.C. Taxas de retrogradação e balanço sedimentar em praias sob risco muito alto de erosão no município de Ubatuba (Litoral Norte de São Paulo). Quaternaryand Environmental Geosciences, v. 1, p. 25-41, 2009. http://dx.doi.org/10.5380/abequa.v1i1.14489

SUGUIO, K.; MARTIN, L.; BITTENCOURT, A.C.S.P.; DOMINGUEZ, J.M.L.; FLEXOR, J.M.; AZEVEDO, A.E.G. Flutuações do nível relativo do mar durante o Quaternário superior ao longo do litoral brasileiro e suas implicações na sedimentação costeira. Revista Brasileira de Geociências, v. 15, p. 273$286,1985$.

SUGUIO, K.; ÂNGULO, R.J.; CARVALHO, A.M.; CORRÊA, I.C.S.; TOMAZELLI, L.J.; WILLWOCK, J.A.; VITAL, H. Paleoníveis do Mar e Paleolinhas de Costa. In: SOUZA, C.R.G.; SUGUIO, K.; OLIVEIRA, A.M.S.; OLIVEIRA, P.E. (eds). Quaternário do Brasil. Ribeirão Preto: Holos, 2005. p. 114-127.

TCE-RJ, TRIBUNAL DE CONTAS DO ESTADO DO RIO DE JANEIRO. Estudos socioeconômicos. Municípios do Estado do Rio de Janeiro. Rio de Janeiro: Tribunal de Contas do Estado do Rio de Janeiro, 2017. https://www.tcerj.tc.br/portalnovo/publicadordearquivo/relatorio_de_atividades_do_tce_rj 
TEIS, M.A.; TEIS, D.T. A Abordagem Qualitativa: A Leitura no Campo de Pesquisa. Biblioteca On-line de Ciências da Comunicação, v. 1, p. 1-8, 2006.

THIRY-CHERQUES, H.R. Saturação em pesquisa Qualitativa: Estimativa empírica de dimensionamento. Af-Revista PMKT, n. 3, p. 20-27, 2009.

VIANNA, L.F.N.; BONETTI, J.; POLETTE, M. Gestão costeira integrada: análise da compatibilidade entre os instrumentos de uma política pública para o desenvolvimento da maricultura e um plano de gerenciamento costeiro no Brasil. Revista de Gestão Costeira Integrada, v. 12, p. 357-372, 2012. https://doi.org/10.5894/rgci335 